\title{
The Cost of Workplace Flexibility for High-Powered Professionals
}

\section{Citation}

Goldin, Claudia and Lawrence F. Katz. 2011. The cost of workplace flexibility for high-powered professionals. Annals of the American Academy of Political and Social Science 638(1): 45-67.

\section{Published Version}

doi:10.1177/0002716211414398

\section{Permanent link}

http://nrs.harvard.edu/urn-3:HUL.InstRepos:8737996

\section{Terms of Use}

This article was downloaded from Harvard University's DASH repository, and is made available under the terms and conditions applicable to Open Access Policy Articles, as set forth at http:// nrs.harvard.edu/urn-3:HUL.InstRepos:dash.current.terms-of-use\#OAP

\section{Share Your Story}

The Harvard community has made this article openly available.

Please share how this access benefits you. Submit a story.

\section{Accessibility}


The Cost of Workplace Flexibility for High-Powered Professionals

Claudia Goldin

Lawrence F. Katz

Biographies and acknowledgments:

Claudia Goldin is Henry Lee Professor of Economics at Harvard University and Director of the Development of the American Economy Program at the NBER. Lawrence F. Katz is Elizabeth Allison Professor of Economics at Harvard University and a Research Associate of the NBER. They are the co-authors of the Race between Education and Technology (Belknap Press 2008). This paper summarizes part of their on-going project on career and family. A longer, and more complete, version of the paper will be issued as "The Career Cost of Family." Goldin gratefully acknowledges sabbatical support from the Alfred P. Sloan Foundation and data from the American Veterinary Medical Association.

\section{Abstract (132 words)}

We study the pecuniary penalties for family-related amenities in the workplace (e.g., job interruptions, short hours, part-time work, and flexibility during the workday), how women have responded to them, and how the penalties have changed over time. The pecuniary penalties to behaviors that are beneficial to family appear to have decreased in many professions. Selfemployment has declined in many of the high-end professions (e.g., pharmacy, optometry, dental, law, medicine, and veterinary medicine) where it was costly in terms of workplace flexibility. We conclude that many professions have experienced an increase in workplace flexibility driven often by exogenous factors (e.g., increased scale of operations; shifts to corporate ownership of business) but also endogenously because of increased numbers of women. Workplace flexibility in some positions, notably in the business and financial sectors, has lagged.

Keywords: Workplace flexibility, occupational choice, compensating differentials, careers, professions, gender, family 


\section{A. Introduction}

We explore the cost of workplace flexibility for occupations at the upper end of the education and income spectrums. We study the pecuniary penalties for various family-related amenities, how women have responded to them, and whether the penalties have changed over time. We find that the costs of workplace flexibility vary greatly across high-end careers. More important is that the cost appears to have decreased over time in many of them.

The costs of workplace flexibility include penalties to labor supply behavior that is more compatible with having a family. These behaviors include job interruptions, short hours, parttime work during some part of the working life, and work flexibility during the day. Selfemployment in professions with office practices (e.g., dentists) or in retail sales (e.g., pharmacists) often requires more hours of work because of classic agency problems. Selfemployment in these professions allows less workplace flexibility. In other professions, however, where self-employment does not involve considerable investment in capital and the management of other workers (e.g., management consulting), it gives women the ability to employ themselves for shorter hours and with greater flexibility than allowed in the corporate sector.

Individuals make career choices at various moments in their life cycles with imperfect knowledge about the workplace flexibility penalties and uncertainty about their family responsibilities. People sort across careers for various reasons and the career and family goal is one of them. As the penalties to family have decreased in various careers, women have flocked to them.

The choice that employees make is not between having some workplace flexibility and having no workplace flexibility. Their decision concerns how much they are willing to pay for flexibility. The cost of flexibility differs by industry and by occupation. Employees have different demands for workplace flexibility and are willing to pay different amounts. The equilibrium cost of workplace flexibility is the tradeoff between earnings and the amenity. It derives from the supply and demand for workplace flexibility.

Many occupations at the upper end of the income and education distributions have experienced large changes in the costs of providing flexibility as well as in the demand for 
workplace flexibility. The labor market equilibrates the two sides of the market (the demand for flexibility and the supply of it) and that generates different amounts of workplace flexibility and different costs.

We develop a framework to understand the impact of demand-side changes by individuals who want a more family-friendly workplace and the impact of supply-side changes by firms with changing costs of providing these amenities. We then present vignettes for various high-end professions and subspecialties within professions. The implications of the framework are considered concerning changes in the cost of the amenity, the fraction female in the profession or subspecialty, the gender gap in earnings, the fraction working part-time, and the fraction self-employed. We end with an analysis of about 90 of the highest paying and most skilled occupations showing that some impose greater penalties on women and men who would like workplace flexibility than do others.

B. A Compensating Differentials Framework of Gender Differences in Earnings and Occupations

Certain occupations at the high end are more enabling of family than are other highincome jobs and some firms are more family friendly than are others. Many professions now have more workplace flexibility than they had a few decades ago. What these statements generally translate into is that occupations and professions differ in their pecuniary penalties to certain characteristics that are considered family-friendly amenities. What happens in the labor market when there is a shift in worker demand for greater flexibility? What happens when there is a technological change that reduces the costs of providing such flexibility? To explore these questions we develop a model of an occupation having an amenity that is costly to offer.

We model the provision of the amenity, such as workplace flexibility, by borrowing from Sherwin Rosen’s (Rosen 1986) model of “compensating differentials,” which in turn is a formalization of ideas dating back to Adam Smith. ${ }^{1}$ The model reveals the differential impacts

\footnotetext{
${ }^{1}$ Our framework is, as well, a generalization of that in Mincer and Polachek (1974), which emphasizes the impact of career interruptions for the gender wage gap and occupational choice. Whereas Mincer and Polachek treat the mix of jobs as given, we endogenize it.
} 
of an increase in the demand for the amenity (or a decreased willingness to work with the disamenity) and a decrease in the cost of providing the amenity (or reducing the disamenity).

We do not have the space here to explain the full model in detail. It is contained in our longer work (Goldin and Katz 2011). Various aspects of work are disamenities to some but are not overly bothersome to others. We focus on workplace flexibility, but these disamenities can include workplace hazards among others. The ability to shift hours during the day may be highly valued by some but not worth much to others. The fact that some professions heavily penalize job interruptions and disproportionately tax short hours may be important to some workers and not to others. The same is true with other aspects of workplace family friendliness including the provision of on-site daycare and paid family leave policy.

We model the amenity of job flexibility as a discrete variable. Jobs are either inflexible or flexible. The inflexible jobs come with a disamenity $(\mathrm{D}=1)$. Alternatively, jobs can be flexible and not have the disamenity $(\mathrm{D}=0)$.

On the demand side of the market for the amenity, workers value income and they are assumed to be heterogeneous in their tastes for the disamenity (D). Assume that the compensating differential in earnings between a job with the disamenity and one without is $\Delta \mathrm{W}$. Workers who have a high value for the amenity will opt for the job without the disamenity and will pay $\Delta \mathrm{W}$ for it. Alternatively, those who have a low value for it, will not.

On the supply side of the market, the firms' technologies that produce the amenity (or that ameliorate the disamenity) are assumed to be distributed continuously. Firms are assumed to be heterogeneous in the productivity benefit of the disamenity and thus in the costs of getting rid of it. For some firms or sectors, the provision of part-time work is not costly whereas for others it is. If $\Delta \mathrm{W}^{*}$ is the given wage differential firms are paying to employees who take the disamenity, the firms with lower costs of providing the amenity would do so and firms with higher costs would not.

The equilibrium for the amenity occurs when its supply equals its demand. If the supply of the amenity is equal to the demand for the amenity at the going wage differential, then the market is in equilibrium. If the supply of the amenity was greater than its demand, the price of 
the amenity (the wage differential) would fall, and if the supply were less than the demand, the price of the amenity would rise.

The model can be made relevant to the issues explored here by considering two types of workers: males and females. If at every $\Delta \mathrm{W}$ women demand more of the amenity than men, men will walk away with a higher salary and incur the disamenity, about which they care little.

Two main changes can alter the equilibrium. The first is a labor supply shift. An influx into an occupation of women (who presumably are more willing than men to pay for the amenity) will mean that, at the going wage differential, demand for the amenity will exceed its supply and the price of the amenity will rise. A larger wage differential between jobs with and without the amenity will result, the fraction of jobs offering the amenity will increase, and a greater fraction of men who opt for the amenity will decrease since they are less willing to pay for it.

If, on the other hand, the cost of providing the amenity (or, alternatively, the productive benefit of the disamenity) decreases, more firms would want to offer the amenity at the current wage difference and pressure will mount for $\Delta \mathrm{W}$ to decrease to attract more workers to purchase the amenity. More men and more women will shift into flexible jobs, but it is likely that relatively more women than men will be enticed into these positions. Men, in fact, might shift into the more highly compensated inflexible jobs.

In sum, the framework shows that individuals with a greater willingness to pay for the amenity earn less than others and that a decrease in the cost of supplying the amenity increases their relative earnings. An increase in the supply of individuals who value the amenity will increase the equilibrium amount paid for the amenity and widen the gap in earnings between men and women. We will present evidence for several professions suggesting that the provision of job flexibility changed exogenously and due to supply-side factors. But we will also present evidence showing that the supply of the amenity, and probably its price, was responsive to increased demands for more flexibility within occupations and sectors.

The compensating differentials framework embeds two cases to understand the dynamics of workplace flexibility and gender earning differences in the workplace. One case is that the change in workplace flexibility comes about because of an increase in the group with the greater 
demand for the amenity or comes about because of a change in preferences for the amenity. That is the demand-side case. The implications are: (a) an increase in the cost of the amenity, and by implication an increase in the gender gap of earnings, and (b) an increase in the fraction of the total workforce with the amenity (but a decrease in the fraction of men with the amenity since its price rises). In the other case, the costs to firms of providing the amenity or of reducing the amount of the disamenity decreases. That is the supply-side case. The implications are: (a) a decrease in the cost of the amenity, and by implication a decrease in the gender gap of earnings, and (b) an increase in the fraction of the total workforce with the amenity (and an increase in the fraction of men with the amenity since its price decreases).

In both cases a higher fraction of workers will take the amenity after the change, although it will be greater in the second case. The major difference between the two cases concerns the equilibrium wage difference. In the first case the gender gap in earnings increases; in the second case it falls.

\section{Earnings Penalties for Job Interruptions}

Earnings penalties for job interruptions differ greatly by type of advanced degree and the clearest evidence we have encountered of these penalties comes from our Harvard and Beyond (H\&B) survey data. The H\&B surveyed members of Harvard College graduating classes from 1969 to 1992 (see Goldin and Katz 2008). A large fraction of the women (and men) in these classes - around 60 to 65 percent - pursued one of the four advanced degrees MBA, JD, MD, and $\mathrm{PhD}$.

The penalty incurred from taking time off is largest proportionately for MBAs. The MDs have the lowest penalty and the PhDs and JDs are in the middle of the pack. These penalties are computed from the (log) earnings regressions given in Table 1. The log earnings penalty experienced for individuals from each of the four degree groups had they a job interruption of one-tenth of their post-BA period is 53 log points for the MBAs, 34 log points for the PhDs and JDs but just 17 log points for the MDs. Translated into the fraction of earnings forgone, MBAs give up 41 percent, PhDs and JDs 29 percent and MDs just 16 percent for a job interruption equivalent to 18 months during 15 years after receiving their BA. 
Job interruptions are entered in the regressions as “any job interruption” (a dummy variable) and as the "share of post-BA years" in which the individual was not employed ( a continuous variable). ${ }^{2}$ The penalty for "any job interruption” is substantial for the MBAs and is larger than that for any of the other three degree groups. The MDs have almost no penalty for “any job interruption” and all of their loss comes from the actual time off. The JDs and PhDs are penalized moderately for both.

\section{Occupational Vignettes}

Women at the top of the educational distribution have been heading in great numbers to various professions. As can be seen in the top part of Figure 1 women have increased their presence in many high-end professions, such as medicine, law, and business, less so in dentistry. The fraction female among first year law students increased from around 5 percent in the late 1960s to more than 30 percent in the late 1970s, and reached approximate parity with men in about 2000. The increase among MBAs was also rapid in the 1970s although the levels were lower and continue to be below those achieved by women in law and medicine. In dentistry, which appears to have been eschewed by women, an increase is apparent in the late 1970s.

$<$ Figure 1 $>$

As can be seen in the bottom part of Figure 1, women have also greatly increased their numbers in some of the smaller high-end professions such as veterinary medicine, pharmacy, and optometry, less so in chiropractic medicine. In fact, some of the largest gains can be found in many of the smaller professions. Among these, veterinary medicine is the most striking. Whereas women were less than 10 percent of all graduating veterinarians in 1970, they are almost 80 percent in the most recent years. Optometry, once a male bastion, is about 60 percent female now. Pharmacy graduates are also around 60 percent female now but were 30 percent in the mid-1970s. Women were pharmacy graduates to a greater degree than these other

\footnotetext{
${ }^{2}$ Job interruptions in the H\&B are defined as spells of more than six months (post BA) for which the individuals state they are not employed at all and are not in school.
} 
professions in the earliest years in the figures, but they have clearly increased their numbers even as the requirements to be a practicing pharmacist have increased. ${ }^{3}$

But have women been heading in the direction of greater workplace flexibility and a lower price to this choice, or have they simply been going into professions that were previously male-dominated and were at the top of the salary and prestige hierarchy?

In general, women appear to be moving in the direction of choosing professions and specialties within professions that are consistent with their greater desire for workplace flexibility. Although some professions have changed exogenously largely due to changes in the scale of operations, other professions and worksites have changed because of the influx of women. Both changes have altered the tradeoffs between work amenities desired by women, such as workplace flexibility, and their earnings per unit time. It is more difficult to model and analyze the impact that women have had on professions as they have greatly increased their share.

For each of four professions - medicine, veterinary medicine, business, and pharmacywe discuss evidence we have currently assembled on aspects of workplace flexibility, earnings tradeoffs, and choice across specialties, practice settings, and worksites. These "vignettes” are suggestive and will form the basis of a larger study. Of the various professions that we have included here the largest in terms of degrees awarded in 2008 is business with more than 155,000 graduates. Medicine is a far second with 15,646 and pharmacy is next with 10,932. Veterinary medicine is the smallest with just 2,504 degrees awarded.

\section{Medicine}

Women have greatly increased their numbers in medicine. But they have increased their relative numbers in some specialties far more than in others, according to the most recent data

\footnotetext{
${ }^{3}$ The American Association of Colleges of Pharmacy, a long standing arbiter of pharmacy credentials, makes recommendations concerning the requirements for first professional degrees in pharmacy. In 1907 a 2-year curriculum was recommended, increased in 1925 to a 3-year curriculum and then in 1932 to a 4year curriculum. In 1960 a 5-year curriculum as part of a BS program was recommended and most recently, in 1992, a 6-year curriculum. The American Council on Pharmaceutical Education adopted accreditation standards requiring the "Pharm.D" program in 1997 and the pharmacy graduating class of 2005 was the last to have the 5-year BS in pharmacy as the standard. See Smith, Wertheimer, and Fincham (2005).
} 
for 2007. As can be seen in the top portion of Figure 2, younger female physicians (under 45 years old) are 42 percent of all physicians (see the "total” group). But they dominate Ob-Gyn, pediatrics, dermatology, child psychiatry, and medical genetics in which they are more than half of all specialists. They exceed their average of 42 percent but are less than 50 percent in allergy and immunology, family practice, psychiatry, pathology, public health, general preventive medicine, internal medicine, and forensic pathology. ${ }^{4}$ The bottom portion of Figure 2, which continues the graph, reveals that the younger group of female physicians are rare in fields like gastroenterology, otolaryngology, plastic surgery, aerospace medicine, radiology, cardiology, and various surgical specialties (urological, transplant, neurological, thoracic, and orthopedic).

$<$ Figure 2>

Not only are the levels different across the specialties, ranging from almost 70 percent to less than 10 percent, but the rates of increase also differ in interesting ways. The ratio of the two bars (the lighter versus the darker) shows the growth or slowdown of women in each of the specialties relative to men or to all in that specialty. ${ }^{5}$ Women have increased their fraction in all of the specialties and that is not surprising given that women are 42 percent of the under 45 year old group, 46 percent of the under 35 year old group, but 28 percent for all included physicians.

Some specialties have had a large fraction of women for a long time (e.g., pediatrics) whereas other have low fraction of women (e.g., surgical specialties). Some have had extremely large increases in the fraction female, as is the case for Ob-Gyn, dermatology, allergy and immunology, and occupational medicine. Others that were once popular among women (e.g., diagnostic radiology, radiology, and anesthesiology) have had relatively slow growth. On the other hand, some at the low end, such as colon and rectal surgery, gastroenterology, ophthalmology, gastroenterology, and urology, have had large increases in women. What can account for the levels differences and changes in the fraction female among the various

\footnotetext{
${ }^{4}$ Some of the specialties, it should be noted, are far smaller than others. Among those at the high end of the fraction female distribution, public health, occupational medicine, medical genetics, immunology, general preventive medicine, and forensic pathology each contain less than 1 percent of all physicians. Ob-gyn, pediatrics, psychiatry, and family practice each have more than 5 percent of all physicians.

${ }^{5}$ Let $\mathrm{F}=$ females, $\mathrm{T}=$ (females and males), $\mathrm{y}=$ the younger group $(<45$ years $)$ and $\mathrm{a}=$ all physicians in each specialty, $\mathrm{i}$. Then the bar for the younger group is $\left(\mathrm{F}_{\mathrm{i}}^{\mathrm{y}} / \mathrm{T}_{\mathrm{i}}^{\mathrm{y}}\right)$ for each specialty and $\left(\mathrm{F}_{\mathrm{i}}^{\mathrm{a}} / \mathrm{T}_{\mathrm{i}}^{\mathrm{a}}\right)$ for all ages. The ratio of these two ratios gives the growth of women in each specialty to all physicians in each specialty, if the younger group represents the increase in physicians during some time period.
} 
specialties?

We have used various printed guides (e.g., Iserson 2006, Freeman 2007) intended to assist medical students in making decisions about residency and fellowship programs, to obtain information on the requirements and work life for each of the specialties. Because requirements for each specialty can change, we first examine the relationship between fairly recent data on clinical and patient hours per week and the fraction female among those less than 45 years old.

Women appear to be attracted to specialties with lower weekly hours, although the causation could be that specialties with a higher fraction female have lower average hours because women work fewer hours by choice. ${ }^{6}$ The surgical specialties tend to be in the higher end of the hours distribution but there may be other reasons why women eschew many of the surgical fields, including their longer residency period. But even without the various surgical specialties, the relationship between hours and fraction female is still negative.

Weekly clinical and patient hours do not provide a complete picture of the time demands of physicians. A complementary indicator of workload, and one that is more exogenous than actual hours, is whether the specialty has on-call, emergency, or night hours on a regular basis. We created an indicator variable of this characteristic. The specialties that have relatively few younger female physicians are generally those with more excessive demands. Among the 26 specialties, with information on workload characteristics, 8 of the 13 with the lowest fraction female had high demands but just 3 of the 13 with the highest fraction female had high demands (one of which is Ob-Gyn). Women, in addition, are less apt to be in specialties with the longest residency and fellowship training periods.

Some physician specialties have undergone large changes in the fraction female during the past several decades. The reason for the change often reveals much about the demand for workplace amenities. Gastroenterology provides one of the best examples. For years this specialty had among the lowest fractions female. In 2007 just 5 percent of these specialists were women among those 55-64 years old, 11 percent were among those 45 to 54 years old, 18 percent were in the 35 to 44 year old group, and 30 percent were of those less than 35 years old.

\footnotetext{
${ }^{6}$ The positive outliers are two fields (pediatrics and Ob-Gyn) that have a client base that is disproportionately female or child.
} 
One of the reasons for the large shift of women to this specialty is the expansion of routine and scheduled colonoscopies. That growth meant a large increase in the demand for those who perform colonoscopies, such as gastroenterologists and colon and rectal surgeons. ${ }^{7}$

\section{Veterinary Medicine}

The fraction female among veterinarians from the 1970s to the present day is among the largest among all the professions, rising from around 10 percent for those graduating more than three decades ago and currently 60 years old, to almost 80 percent for the most recent graduates of veterinary colleges. What are the reasons for women's enormous inroads in this field? Female veterinarians like to emphasize their attraction to the caring nature of their profession, but that aspect of the job has not changed much. Compelling evidence suggests that the increasing ability of many veterinarians to schedule their hours and reduce or eliminate on-call, night, and weekend hours has been a contributory factor.

The organizational changes that transformed many veterinary practices involve the rise of regional veterinary hospitals and other emergency facilities. During nights and weekends these hospitals care for the clients of smaller veterinary practices, allowing these practices to be closed during all but regular daytime hours. Another factor is that female veterinarians appear to shy away from being equity stakeholders in their practices and there is a recent movement to larger, corporate ownership of veterinary practices. These two factors are not the only reasons for the relative increase of female veterinarians.

Because the total number of active veterinarians in the nation is small (probably around 60,000), the more usual sources, such as CPS and even the decennial census, do not yield adequate information with which to explore the preferences of female veterinarians relative to male veterinarians and understand the time series changes. ${ }^{8}$ We are fortunate to have a data set of almost 4,000 veterinarians in 2007 from a biennial survey taken by the American Veterinary

\footnotetext{
${ }^{7}$ The increase in the fraction female with age for colon and rectal surgeons is similar to that for gastroenterologists. These are almost ten times as many gastroenterologists as there are colon and rectal surgeons. Although the former do many of the scheduled colonoscopies and endoscopies, colon and rectal surgeons also perform many colonoscopies. See American Medical Association (2009). ${ }^{8}$ Data at <http://bhpr.hrsa.gov/healthworkforce/reports/factbook02/FB505.htm> gives 60,100 total active veterinarians for the year 2000 or 21.8 per 100,000 population in the U.S.
} 
Medical Association (AVMA). ${ }^{9}$

The AVMA data show that female veterinarians decrease their hours of work a few years after joining a practice and then, if the cross section data provides any guide, continue to work considerably shorter hours than male veterinarians. Their hours of work average around 44 per week whereas male veterinarians average around 53.

Related to the data on hours of work is that, among the ever-married group, more than 20 percent of female veterinarians work part-time from their late thirties to their early fifties (once again, if the cross section is a reasonable guide). Among male veterinarians, less than 5 percent work part-time. The interesting finding for female veterinarians is that part-time work is relatively the same from around the mid-thirties to the early-fifties. It would appear that evermarried women decide to work shorter hours or to have no on-call, night, and weekend hours when young and then stay with that routine.

About 40 percent of female veterinarians in private practice in 2007 (versus 27 percent of male veterinarians) stated that they put in no emergency hours. Rural veterinarians and those outside major urban areas put in more emergency hours than do those in large cities and many work on-call and have night duty. But hours in general for veterinarians are lower than are those of physicians and a greater fraction work part-time.

A far higher fraction of male than female veterinarians in private practice have an equity stake in their practice and men have considerably more invested conditional on any equity stake. These relationships exist across all ages and are not just a product of the more recent surge in female veterinary students. The fraction of women with an equity stake is less than half that for men at all ages. Whereas about 75 percent of male veterinarians in private practice in their late forties and fifties have some equity stake in their practice, about 35 percent of female veterinarians do. In addition, conditional on having any equity stake, male veterinarians have a far higher amount invested in their practice. On average, men have almost \$100K more than

\footnotetext{
${ }^{9}$ The published version is American Veterinary Medical Association (2007).
} 
women invested in their practice, given their age. ${ }^{10}$

An important factor to emphasize is the impact of taking any time off from veterinary practice. We showed earlier that the career penalty from job interruptions, using our Harvard and Beyond (H\&B) data, varied considerably by profession. MDs had the lowest penalties and MBAs the highest. The penalty for time off using our veterinary data is relatively small - just 9 log points for any time off. It is closest to the estimates for the MDs in the H\&B data than it is to that for any of the other professions. When the specification is identical to the one we use for the H\&B data (Table 1), the impact of any time off is no different from zero and the entire impact of job interruptions comes from the amount of time off rather than whether any time was taken.

In sum, women have greatly increased their numbers in veterinary medicine. There is no specialty in medicine that has a greater fraction female and none in which in the fraction female has increased as much since 1970. Female veterinarians state that they find the field attractive because of their love of animals and because they do not have to interact as much with the public as in medicine. But the extraordinary relative growth among women is probably due to changes in the organization of the industry which, in turn, may have been hastened by a critical mass of female veterinarians.

\section{MBAs: The Corporate and Financial Sectors}

We noted earlier that among the most numerically important professions in our H\&B sample, MBA women have the lowest labor force participation rates, the longest periods of job interruption when they have children, and forfeit the largest fraction of their income when they take time off. To understand why MBA women's career trajectories are more extreme than those of other female professionals, and to comprehend how women have fared in this highly lucrative sector, Marianne Bertrand and the two of us surveyed the 1990 to 2006 MBA graduates from the Chicago Booth School (Bertrand, Goldin, and Katz 2010).

Our sample consists of about 2,500 MBA graduates, 25 percent of whom are female. Because the survey is retrospective, the resulting data set contains more than 18,000 person-

\footnotetext{
${ }^{10}$ The $\$ 100 \mathrm{~K}$ figure comes from a regression of the amount of equity invested in the practice, conditional on being greater than zero, on age, age squared, and a dummy for male. The coefficient on the male dummy in a regression of $\log$ (equity) and the same covariates is about 70 log points.
} 
years on earnings and hours, other employment information, and detailed information on marriage and family.

At start of their careers, earnings by gender are almost identical. But five years out a 30 log point difference in annual earnings develops and 10 to 16 years out the gender gap in earnings grows to 60 log points (or that uncorrected women earn 55 percent what men do). Three factors in our data set can explain 84 percent of the gap. Training prior to MBA receipt, e.g., finance courses, GPA accounts for 24 percent. Career interruptions and job experience account for 30 percent, and differences in weekly hours are the remaining 30 percent. All aspects of the gender labor supply gap expand with time since MBA including the fraction not working in a year, the part-time share, and hours worked among full-time workers.

The dynamics of gender differences in labor supply can be seen in changes in hours per week with time since MBA, share working full-time, full-year (FT-FY), which declines to about 0.60 for women, and the share not working which rises to about 0.17 for women. Thus at 10 to 16 years out 23 percent of Booth School MBA women who are in the labor force work part-time. Cumulative time not working is about one year for all women 10 to16 years after the MBA. At 10 to16 years out 60 percent work FT-FY, 51 percent do for those with children; the rest is about equally divided between part-time (PT) work and opting-out. Interestingly, more than half of those working PT employ themselves.

The gender gap in earnings, as we noted, is small directly following MBA receipt and then widens substantially. But even this gap can be largely "explained" by the three main factors: training prior to the MBA and MBA coursework, career interruptions and job experience and hours worked. Importantly, there is a large penalty from taking any time out, which is about two-thirds of the total penalty from job interruptions.

Not surprisingly children are the main contributors to labor supply differences such as career interruptions and hours worked. Women with children have labor force rates that are 20 percentage points lower than are men's or women's without children. They work 24 percent fewer hours than men or women without children. The impact of children on female labor supply differs strongly by spousal education or income. MBA moms with high earning spouses (> \$200K, in 2006\$) have labor force rates that are 18.5 percentage points lower than those with 
lesser earnings spouses. They work 19 percent fewer hours (when working) than those with median or lower earnings spouses. MBA moms with non-high earning spouses show no effect on participation from kids, but they do work fewer hours than women without kids. The effect of husband's income, moreover, holds up in individual fixed-effects estimation.

Another important result is that the impact of a birth on labor supply grows over time in an individual, fixed-effects estimation. The effect after one year is about 60 to 70 percent the effect measured at five-plus years. A year after a first birth, women's hours are reduced by 17 percent and their participation by 13 percent. But three to four years later, hours decline by 24 percent and participation by 18 percent. It is as if some MBA moms try to stay in the fast lane but ultimately find it is unworkable. The increased impact years after the first birth, moreover, is not due to effect of additional births.

One of the most revealing parts of the analysis, and one that hints at the mechanism, is to divide the sample by the income of the husbands. Women with richer husbands decrease their participation by 31.5 percentage points, work 20 percent fewer hours, and earn about $\$ 200 \mathrm{~K}$ less at five years since the first birth than they otherwise would. The changes, moreover, increase significantly with time since the birth. Those with lower-income husbands do not decrease their participation and have a far lower "hit" to their income, although they do work fewer hours.

Women who marry high-earnings spouses and who do not have children work more, not less, than those who marry the lower-earnings spouses. The interaction of kids and high earning husbands is what matters.

Part-time work in the corporate sector is uncommon and part-timers are often selfemployed (more than half are at 10 to16 years out). Because of the use of self-employment, the opt-out group is actually smaller than the part-timers. Disparities in career interruptions and hours worked by sex are not large but the corporate and financial sectors impose heavy penalties on deviation from the norm. Some female MBAs with children, especially those with high earning husbands, find the tradeoffs too steep and leave or engage in self-employment.

In sum, the MBA lure for women is large - incomes are substantial even though they are far lower than those of their male peers. But some women with children find the inflexibility of the work insurmountable. Some leave or become self-employed. Gender differences in labor 
supply are largely driven by the presence of children and those with well-off spouses exit the labor force more often and work fewer hours. MBA moms with less well-off spouses employ more childcare services, whereas those with high income spouses who drop out take care of their own kids. When MBA moms leave the labor force, they give "family" as the reason, not career, and therefore it does not appear that MBA moms are forced out.

\section{Pharmacy}

The pharmacy industry experienced large structural changes precisely when female pharmacists greatly increased in number. Women were about 8 percent of all pharmacists in 1966 and are almost 60 percent today. Similarly, the fraction female among pharmacy school graduates increased from 14 percent in the mid-1960s to almost 70 percent today (see Figure 3).

$<$ Figure 3 $>$

Pharmacists are found in several sectors. The most important numerically is retail sales, but pharmacists are also employed in hospitals, government, industry, and academia. About 55 percent of all full-time pharmacists are employed in retail today, 25 percent in hospitals, and the remaining 20 percent in the other sectors. But in 1974 almost 75 percent of all pharmacists were in retail sales.

The vast majority of pharmacists are now employees, either staff members or managers. In the year 2000, just 7.6 percent of all pharmacists were owners or partners and a mere 5.6 percent were self-employed in 2007. In both years men were owners at four times the rate of women. In contrast, more than 35 percent of all pharmacists were self-employed in 1970 and 30 percent were owners or partners in 1974. Increased pharmaceutical employment in chain stores and supermarkets has been the largest single reason for these industry changes. ${ }^{11}$

The fraction of pharmacists who are owners or employees in independent practice also declined substantially, a fact that is related to the decline of ownership and the decreased fraction of pharmacists in retail. In the late 1950s about 75 percent of all pharmacists were owners or

\footnotetext{
${ }^{11}$ The 2000 figure comes from Midwest Pharmacy Workforce Research Consortium (2000) and is nearly identical to the 2000 figure from the U.S. population census. The 2007 figure is from the American Community Surveys for 2006-08 (see Table 2). The 1970 figure is from the data underlying Table 2 and that for 1974 is from Northrup, Garrison, and Rose (1979).
} 
were employed by an independent practice; in 197445 percent were and today just 14 percent are. All of these changes occurred just in the retail sector, even though the data given are for all pharmacists, and therefore, their impact on retail establishments alone is much larger. ${ }^{12}$

Each of the changes just mentioned has had major implications for the pharmacy work environment and has decreased the cost to pharmacists of working part-time, part-year, and not being owners or equity stakeholders. The impact on female pharmacists has, in consequence, been large and these changes are probably the single most important factors prompting the enormous increase in female pharmacists.

Interestingly, female pharmacists in the 1950s were employed part-time to about the same extent they are today. They located part-time work in independent pharmacies as assistants to the owner. Their earnings were considerably less than those of the owners who were the residual claimants and the main decision makers. As chain stores expanded, however, more pharmacists became employees. Their earnings no longer included a premium to compensate for the added risk and responsibility and their hours were reduced.

The large organizational and structural changes in the pharmacy industry decreased the costs of offering job amenities in the retail sales. The changes in retail sales reduced the compensating differential to ownership, long hours, and being the residual claimant. Structural changes in pharmacy (and for similar reasons in optometry) were rooted in larger shifts in retailing in America, and elsewhere in the world, that increased the benefits of large scale. It would be hard to assign credit for the spread of WalMart, Target, Costco, CVS, Rite Aid, Walgreens, and other chains that have pharmacies to women's increased numbers in the pharmacy profession. ${ }^{13}$

E. Integrating the Vignettes, the Data, and the Model

Data from the 1970 U.S. decennial census and the 2006-08 American Community Surveys (ACS; termed 2007 for convenience) allows us to compile information on incomes,

\footnotetext{
${ }^{12}$ See sources in Figure 3; ownership data are from Northrup, Garrison, and Rose (1979, table III-10).

${ }^{13}$ See Bottero (1992) for a similar discussion of United Kingdom data.
} 
hours, and self employment for most of the professions just discussed as well as for some others. We present the information in Table 2 for six professions - dentists, lawyers, optometrists, pharmacists, physicians, and veterinarians - for men and women separately and expressed as ratios for males and females. The main findings concern the relative fraction working part-time and self employed, and the gender earnings gap in each profession. Although not shown in Table 2 , the relative increase of women across all the professions was large and these "stock" data reinforce the findings from the "flow" data in Figure 1.

$<$ Table 2>

The fraction of male professionals working part time was considerably less than that for females in all years and all professions. That is not unexpected. What is surprising is that the ratio of males to females working part time increased from 1970 to 2007 in many cases and that in all of those cases the reason is that a greater fraction of men were working part time. In fact, for most of these professions the fraction of women working part time changed only slightly during the past 40 years. Female professionals have always had a fairly large fraction working part time since 1970. Because women's share of total employment in these professions increased, the fraction working part time for the entire group increased.

In most of these professions something changed that enabled women and some men to work part time. That change, it appears, was a decrease in the benefit of the disamenity to the firm and in some cases it is related to the decrease in self employment. Women could always work part time. But the pecuniary penalty for working part time was large and, in consequence, it was less advantageous for them to enter these professions.

Self employment fell for men but remained considerably higher than the rate for women for each of the professions. In some cases, such as medicine and pharmacy, the decrease in self employment for males was considerable. In 197060 percent of all male physicians were self employed (75 percent were in 1940); today just over a third are self employed. In 197038 percent of male pharmacists were self employed (40 percent were in 1940), but just 9 percent are today.

The decrease in self employment is consistent with the theory outlined above in which change in the cost of flexibility is caused by a decrease in the cost to firms of providing the 
amenity. The change from owners to employees meant that these professionals became better substitutes for each other. Whereas an owner of a pharmacy worked or was on-call whenever the pharmacy was open, pharmacists working as employees under a manager can put in as many hours as they want at a constant hourly rate.

Median earnings of men to women decreased in all of the professions listed, somewhat less so in law than in the health-related professions (although without a micro-analysis of the data it is not clear what factors account for the change in relative earnings). Using the compensating differentials framework developed above, the change suggests that technology changes reduced the costs of amenities preferred by women or that there were other supply-side reasons for the change.

Each of the vignettes presented concerned a profession with a rapidly rising female presence during the past four decades. Although some experienced little change in work flexibility during those decades, most underwent substantial change. These organizational changes greatly impacted the ability of these professionals to work fewer hours, engage in parttime work, have job interruptions, and partake in self employment to suit their living styles.

We noted that some professions and specialties were greatly affected by technological change. That was the case, for example, in gastroenterology and colon and rectal surgery, specialties that had a large influx of female physicians in part because of the diffusion of a technology used in a scheduled procedure. Organizational and structural changes occurred in other professions, as in veterinary medicine and pharmacy. Some, however, experienced little or no change. We showed that many of the occupations that employ MBAs impose large penalties for deviance from the norm of long hours and no job interruptions and that some medical specialties still require night, weekend, and on-call hours.

We have made a case for the exogeneity of change in the pharmacy and optometry sectors with the rise of chain and multi-good stores with pharmacies and eye glass dispensaries. Similarly, in veterinary medicine scale advantages in the use of expensive medical equipment and the hiring of veterinary specialists prompted the rise of regional veterinary hospitals. These hospitals enable veterinarians in private practice to eliminate night, weekend, and vacation hours. The appearance of emergency veterinary facilities preceded the increase of female veterinarians, 
but these facilities took off after the expansion in female veterinarians. Some of the growth of regional veterinary hospitals may, therefore, have been an endogenous response to an increased demand by veterinarians for shorter and more flexible hours.

Similarly, for some medical specialties, such as pediatrics, the high and increasing fraction female of the total group may have led to changes in practice settings and enabled greater amounts of part-time work. Surveys of the American Academy of Pediatrics show that the fraction of female pediatricians working part-time increased from 28 percent in 2000 to 32 percent in 2003, and to 36 percent in 2006 (Cull, O’Connor, and Olson 2010). That for male pediatricians increased from 4 to 8 percent from 2000 to 2006. The increase, moreover, was found across all age groups but was greatest for younger and older pediatricians.

The changes noted in the previous section concerning the decrease in self employment and the increase in part time work, would probably have decreased the earnings of those who placed only a small value on the amenity. That is, in some professions the ratio of female to male earnings should have increased. The evidence in Table 2 supports that implication. Relative earnings of women increased in almost all professions and especially in those, like pharmacy, optometry, and veterinary medicine, in which self employment declined and probably did so for exogenous reasons.

Regressions using the micro-data for the ACS (2006 to 2008) confirm that the decrease in self employment could have increased the relative earnings of women in many professions. Across all high-education professions in which the self employed are a relatively high fraction, men who are self employed earn more than their employee counterparts but self-employed women do not. ${ }^{14}$ The detailed information on veterinarians from the AVMA data corroborates that ownership greatly increases earnings and that the amount of equity is important. Because women hold less equity, they gain less from ownership.

Another implication of the theory is that as the cost of providing the amenity decreases the group that values it most (generally women) will increase relative to the group that values it

\footnotetext{
${ }^{14}$ Eleven occupations are considered for which the fraction self employed exceeds around 25 percent and mean years of education exceeds 16 . The regression of log income (including business and farm income) holds various factors constant, such as potential job experience, hours, weeks, years of education, race and region. The regression excludes lawyers for whom self employment is more ambiguous.
} 
least (generally men). As the premium to residual claimants and owners decreases, those who prefer ownership will leave for, or train, in another occupation. In professions such as pharmacy and veterinary medicine, the increase in the fraction female may have been fostered both by an increase in women, who wanted the amenity at lower cost, and a decrease in men, who wanted the higher compensation awarded to those who were willing to accept the disamenity. In professions like dentistry and chiropractic medicine, self employment decreased far less and the fraction female did not increase as much as in other professions.

\section{F. A Bigger Picture and a Conclusion}

We have examined a small number of important, high end occupations in details. We have found that family friendliness differs in terms of the "cost" to the workers and to the firm, and that exogenous and endogenous changes have altered these costs.

To understand earnings differences between men and women more generally and the implicit role of workplace amenities, we examine the relative incomes of men and women in the top 87 occupations by male income. ${ }^{15}$ After accounting for potential experience, hours worked, weeks worked, and other observable factors, the remaining difference between men and women by occupation is largely due to the penalties imposed on women for greater job interruptions and their need for more flexibility. The results for 2006-2008 given in Figure 4 are striking.

$<$ Figure 4 $>$

Each dot is one of the occupations listed in the census (there are 465 in total). The horizontal axis gives (male) income in natural logs and the vertical axis gives the earnings gap in log points (approximately the percentage penalty) between the average man and woman in an occupation given potential job experience, hours of work, weeks of work, region, and race. ${ }^{16}$ The occupations are divided into those that concern business, health, science, technology, and all others.

\footnotetext{
${ }^{15}$ The top 87 by male income includes all of those above and including post-secondary school teachers. ${ }^{16}$ The sample includes 25 to 64 year olds who work full-time (> 34 hours per week), full-year (> 39 weeks per year).
} 
All 87 occupations are situated just at or below the horizontal axis. That is, in all occupations women make less than men given the somewhat rich group of covariates included in the regression. More interesting is the manner in which the occupations group. The business occupations (squares) are generally the most negative, whereas the technology occupations (light triangles) are the most positive. The health occupations (diamonds) are mixed with those having the greatest fraction self employed being the most negative and the ones that had decreases in self employment being the least negative.

Business occupations, it was previously noted, place heavy penalties on employees who deviate from the norm. But why do the technology occupations appear to penalize women far less? One possibility is that the technology occupations are so recent that their work organizations are structured to deal better with a labor force that needs greater work flexibility.

We have estimated the same equation across all occupations in 1980. The results (not shown here) reveal the enormous change in the presence of women in high-end occupations and in their relative (corrected) remuneration during the four decades that separate the two periods. In 1980 the various health professions were at the very low end of the female coefficient distribution, meaning that they penalized women the most. The business professions were also low but there were not as many of them. The technology occupations penalized women the least but not as low as in 2006-08. And far fewer women were employed in upper-end occupations.

In sum, we have examined the relationships among workplace conditions, the costs and the benefits of various workplace amenities, and the fraction female in professions requiring substantial educational investment. We have accomplished this by studying several professions in detail and the implications of a model of compensating differentials. Our main findings are that occupations differ in the degree to which workplace amenities related to flexibility are effectively taxed. Furthermore, these amenities have become less expensive in many healthrelated occupations as well as in the technology sector. 
Table 1: Penalties from Job Interruptions by Highest Degree: Log Earnings Regressions for Four Career Tracks using the Harvard and Beyond Data

\begin{tabular}{lcccc}
\hline \hline Log (Annual Earnings) in 2005 & $(1)$ & $(2)$ & $(3)$ & $(4)$ \\
& MBA & JD & MD & PhD \\
\hline Female & -0.441 & -0.370 & -0.332 & -0.310 \\
& $(0.0979)$ & $(0.0667)$ & $(0.0466)$ & $(0.0509)$ \\
Job interruptions $\geq 6$ months & & & & \\
Any & -0.449 & -0.299 & -0.0637 & -0.368 \\
Share of post-BA years & $(0.103)$ & $(0.0743)$ & $(0.0687)$ & $(0.0664)$ \\
& -0.819 & -0.463 & -1.09 & 0.297 \\
GPA at Harvard & $(0.487)$ & $(0.351)$ & $(0.382)$ & $(0.276)$ \\
& 0.711 & 0.580 & 0.114 & 0.226 \\
SAT math $\times 10$-2 & $(0.127)$ & $(0.0902)$ & $(0.0690)$ & $(0.0790)$ \\
& -0.0670 & 0.0377 & 0.0311 & 0.0527 \\
SAT verbal $\times 10{ }^{-2}$ & $(0.0721)$ & $(0.0501)$ & $(0.0431)$ & $(0.0442)$ \\
& -0.149 & -0.0419 & -0.112 & -0.107 \\
Dummy variables & $(0.0689)$ & $(0.0498)$ & $(0.0352)$ & $(0.0428)$ \\
Part-time, full-year & & & & \\
Full-time, part-year & -0.452 & -0.661 & -0.464 & -0.625 \\
& $(0.193)$ & $(0.145)$ & $(0.143)$ & $(0.129)$ \\
Part-time, part-year & -0.785 & -0.786 & -0.608 & -0.734 \\
49 Harvard concentrations & $(0.162)$ & $(0.112)$ & $(0.0707)$ & $(0.0969)$ \\
Year of Harvard graduation & -1.67 & -1.67 & -1.88 & -1.43 \\
$R^{2}$ & $(0.149)$ & $(0.123)$ & $(0.126)$ & $(0.103)$ \\
Number of observations & Yes & Yes & Yes & Yes \\
Penalty from job interruptions of & 53.1 log & 34.5 log & 17.3 log & 33.8 log \\
0.1 of post-BA years & points & points & points & points \\
\hline \hline
\end{tabular}

Sources: Harvard and Beyond data. See Goldin and Katz (2008). The full sample is used here and consists of three “cohorts” of Harvard College graduates: graduating 1969-1972 (plus women from 1973), 1979-1982, 1989-1992.

Notes: The dependent variable is annual earnings in 2005. Standard errors are in parentheses under the coefficients. The omitted dummy for work status is full-time, full-year. Dummy variables for missing GPA and missing SAT are included. The last line ("penalty from job interruptions of 0.1 of post-BA years") is computed form the coefficients under "job interruptions." 
Table 2: Income, Hours, and Self Employment by Sex for Selected Professions: 1970 and 2007

\begin{tabular}{|c|c|c|c|c|c|c|c|}
\hline & & \multicolumn{2}{|c|}{ Males } & \multicolumn{2}{|c|}{ Females } & \multirow{2}{*}{$\begin{array}{c}\mathrm{M} / \mathrm{F} \\
1970\end{array}$} & \multirow{2}{*}{$\begin{array}{l}\mathrm{M} / \mathrm{F} \\
2007\end{array}$} \\
\hline & & 1970 & 2007 & 1970 & 2007 & & \\
\hline \multicolumn{8}{|l|}{ Dentists } \\
\hline & Mean hours/week & n.a. & 39.9 & n.a. & 36.9 & n.a. & 1.081 \\
\hline & Fraction part time & 0.118 & 0.218 & 0.363 & 0.34 & 0.325 & 0.641 \\
\hline & Fraction self employed & 0.898 & 0.724 & 0.411 & 0.505 & 2.185 & 1.434 \\
\hline & Median income & $\$ 22,950$ & $\$ 155,763$ & $\$ 8,250$ & $\$ 103,842$ & 2.782 & 1.500 \\
\hline \multicolumn{8}{|l|}{ Lawyers } \\
\hline & Mean hours/week & n.a. & 48.5 & n.a. & 43.7 & n.a. & 1.110 \\
\hline & Fraction part time & 0.053 & 0.047 & 0.18 & 0.139 & 0.294 & 0.338 \\
\hline & Fraction self employed & 0.575 & 0.37 & 0.345 & 0.2 & 1.667 & 1.850 \\
\hline & Median income & $\$ 18,600$ & $\$ 122,000$ & $\$ 10,550$ & $\$ 90,000$ & 1.763 & 1.356 \\
\hline \multicolumn{8}{|c|}{ Optometrists } \\
\hline & Mean hours/week & n.a. & 41.8 & n.a. & 34.6 & n.a. & 1.208 \\
\hline & Fraction part time & 0.068 & 0.13 & 0.194 & 0.395 & 0.351 & 0.329 \\
\hline & Fraction self employed & 0.831 & 0.679 & 0.484 & 0.397 & 1.717 & 1.710 \\
\hline & Median income & $\$ 18,050$ & $\$ 103,842$ & $\$ 9,250$ & $\$ 86,498$ & 1.951 & 1.201 \\
\hline \multicolumn{8}{|c|}{ Pharmacists } \\
\hline & Mean hours/week & n.a. & 42.9 & n.a. & 37 & n.a. & 1.159 \\
\hline & Fraction part time & 0.05 & 0.078 & 0.361 & 0.272 & 0.139 & 0.287 \\
\hline & Fraction self employed & 0.38 & 0.094 & 0.159 & 0.024 & 2.390 & 3.917 \\
\hline & Median income & $\$ 12,950$ & $\$ 106,788$ & $\$ 8,550$ & $\$ 100,000$ & 1.515 & 1.068 \\
\hline \multicolumn{8}{|c|}{ Physicians } \\
\hline & Mean hours/week & n.a. & 54.7 & n.a. & 49.1 & n.a. & 1.114 \\
\hline & Fraction part time & 0.041 & 0.048 & 0.18 & 0.152 & 0.228 & 0.316 \\
\hline & Fraction self employed & 0.605 & 0.325 & 0.314 & 0.195 & 1.927 & 1.667 \\
\hline & Median income & $\$ 27,150$ & $\$ 186,916$ & $\$ 12,050$ & $\$ 112,128$ & 2.253 & 1.667 \\
\hline \multicolumn{8}{|c|}{ Veterinarians } \\
\hline & Mean hours/week & n.a. & 50.5 & n.a. & 42.5 & n.a. & 1.188 \\
\hline & Fraction part time & 0.045 & 0.061 & 0.321 & 0.23 & 0.140 & 0.265 \\
\hline & Fraction self employed & 0.662 & 0.554 & 0.377 & 0.261 & 1.756 & 2.123 \\
\hline & Median income & $\$ 17,050$ & $\$ 97,000$ & $\$ 9,050$ & $\$ 72,690$ & 1.884 & 1.334 \\
\hline
\end{tabular}

Sources: 1970 U.S. Census of Population; 2007 is 2006-2008 American Community Survey (ACS). 1970 aggregates six 1percent samples and is a 6 percent sample. The ACS is a 1 percent sample and the three years are aggregated. The census data are produced and distributed by the IPUMS.

Notes: The sample for each year consists of individuals who worked at least one week in the previous year. Professions are identified using the contemporaneous occupation codes in each respective 
census. Part time is less than a 35-hour work week. Median incomes are based on wage earnings plus business and farm earnings for those working full-time and full-year (more than 39 weeks per year and more than 34 hours per week) with implicit hourly earnings greater than one-half the minimum wage in that year. Top-coded incomes are multiplied by 1.4 in all years. Incomes are in current dollars. See also Goldin and Katz (2011). n.a. = not available 
Figure 1: Fraction Female among Professional School Graduates, c.1955 to c.2010 Part A: Four Larger Professions

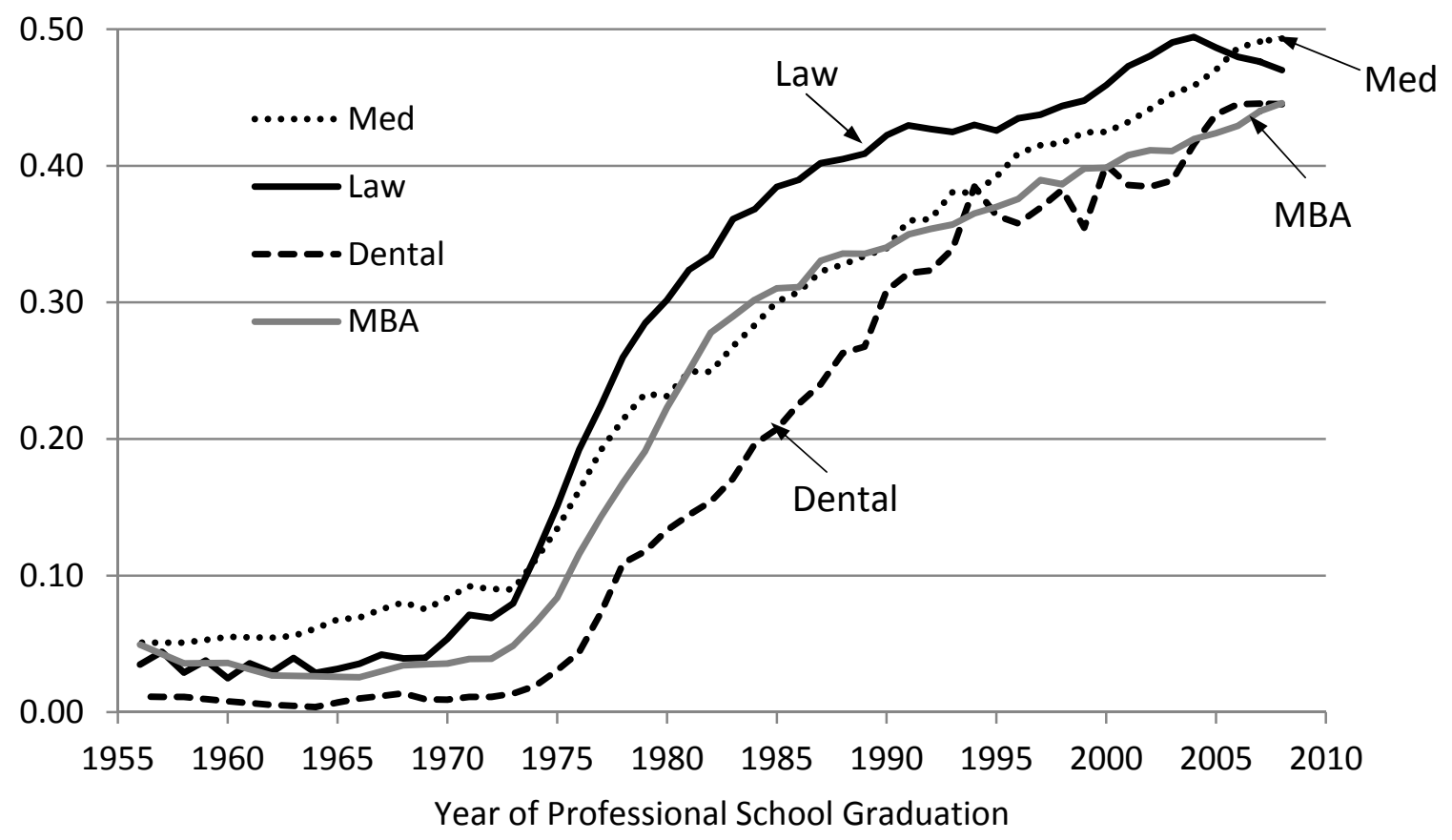

Part B: Four Smaller Professions

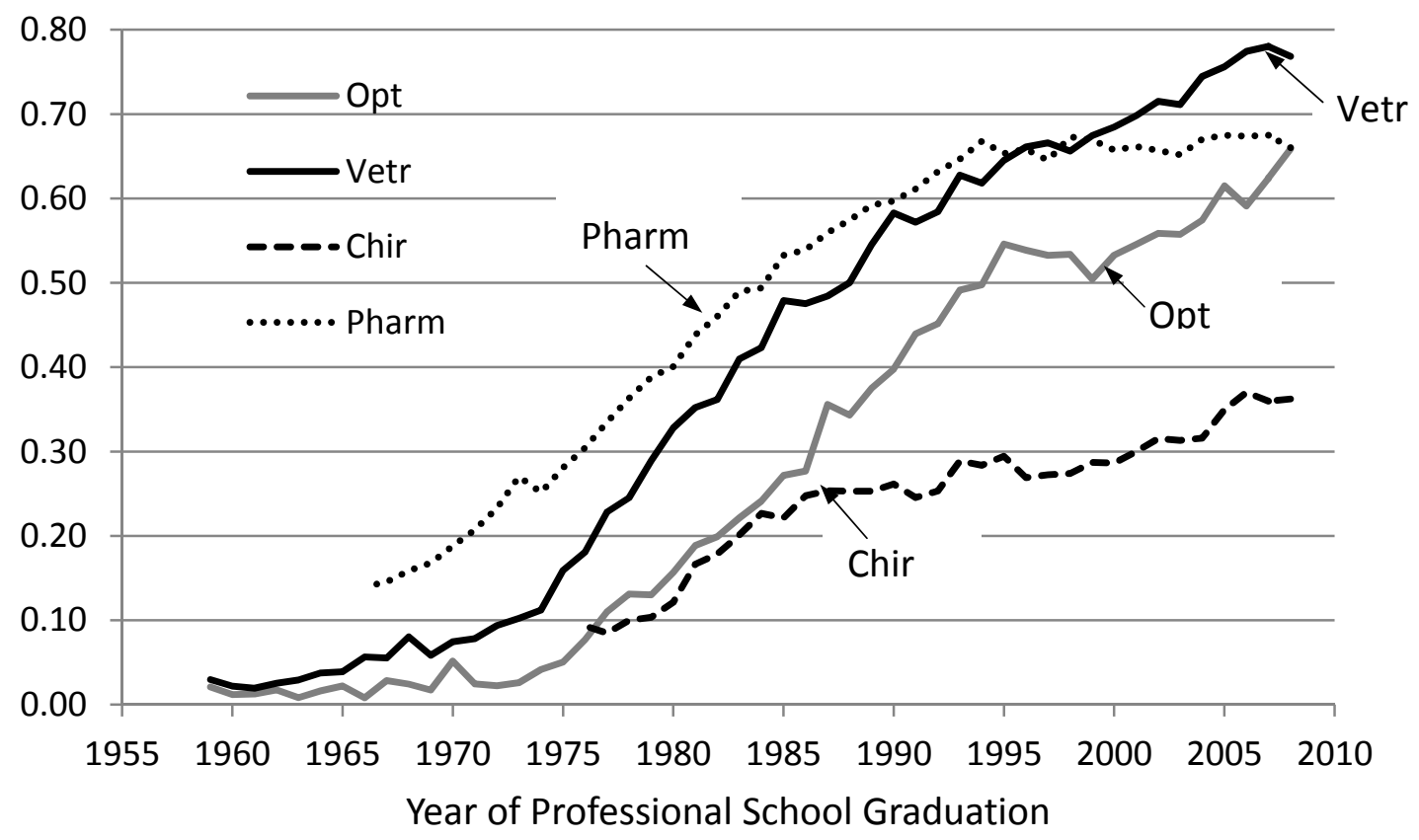

Sources: See data appendix in Goldin and Katz (2011). 
Figure 2: Fraction Female by Physician Specialty and Age of Physician, 2007 Fraction Female

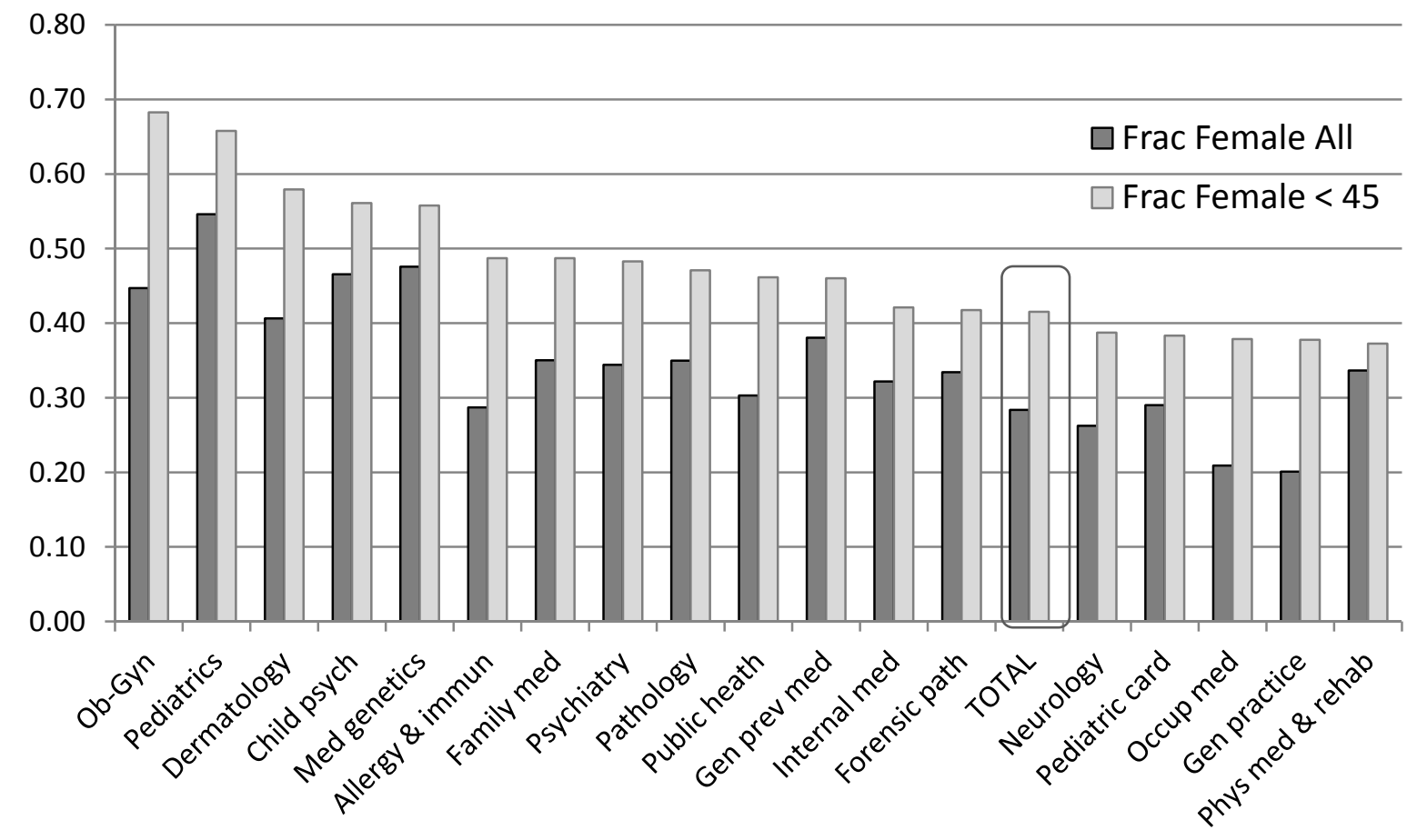

Fraction Female

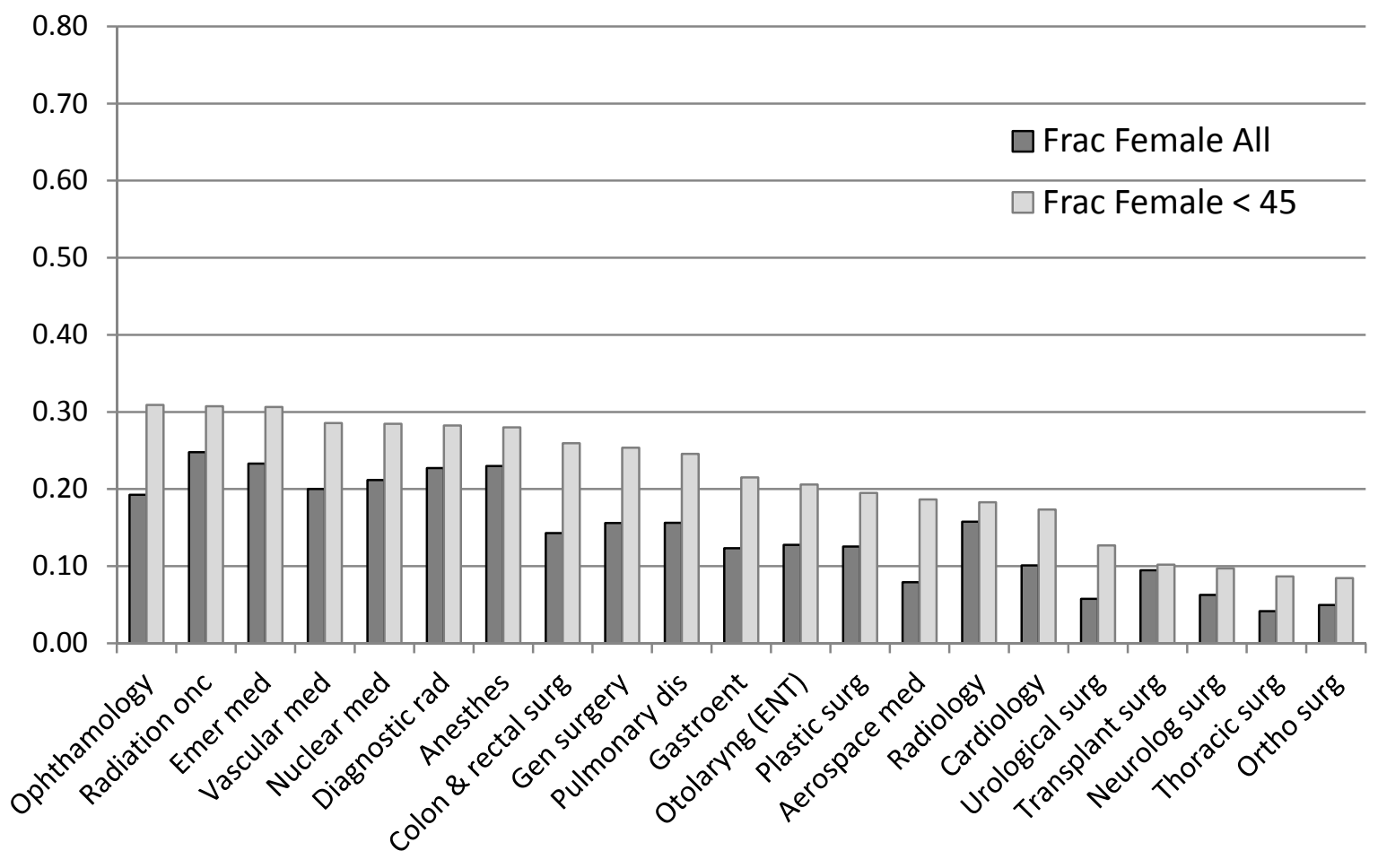

Source: American Medical Association (2009). 
Figure 3: Pharmacists: Fraction Female and Fraction Working in Independent Pharmacies

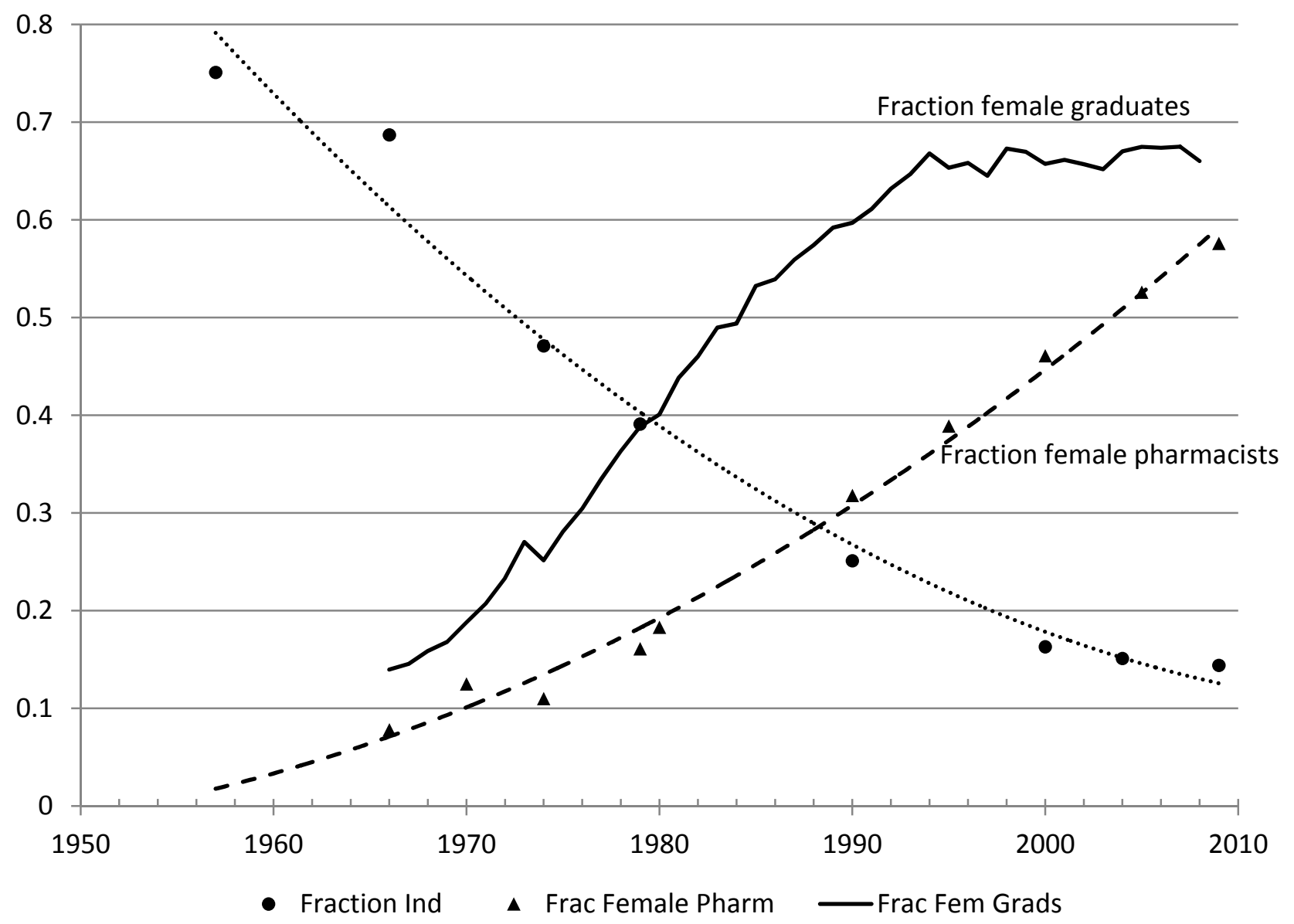

Sources: Fraction female: U.S. Department of Health, Education and Welfare (1969); U.S. Department of Health, Education and Welfare (1978); Mott, Doucette, Gaither, Pedersen, and Schommer (2002); Midwest Pharmacy Workforce Consortium (2000). Fraction independent pharmacists: U.S. Department of Health, Education and Welfare (1969); Fulda (1974); U.S. Department of Health, Education and Welfare (1978); Kapantais (1982); U.S. Department of Health and Human Services (2000). Fraction female graduates of pharmacy programs: see Figure 1.

Notes: A pharmacist in independent practice can be an owner or an employee. "Independent practice" means a unit or series of units for which one of the owners makes the majority of the decisions. Independent practices can have several stores, but are not "chains" in the sense that they are not run by large corporations. Pharmacists can be employed by retail establishments, hospitals, industry, academia, and government. The fraction in independent practice is obtained by taking the number in independent retail practice relative to all active pharmacists. 
Figure 4: Female Earnings Differentials for the 87 Highest Paid Occupations, 2006 to 2008

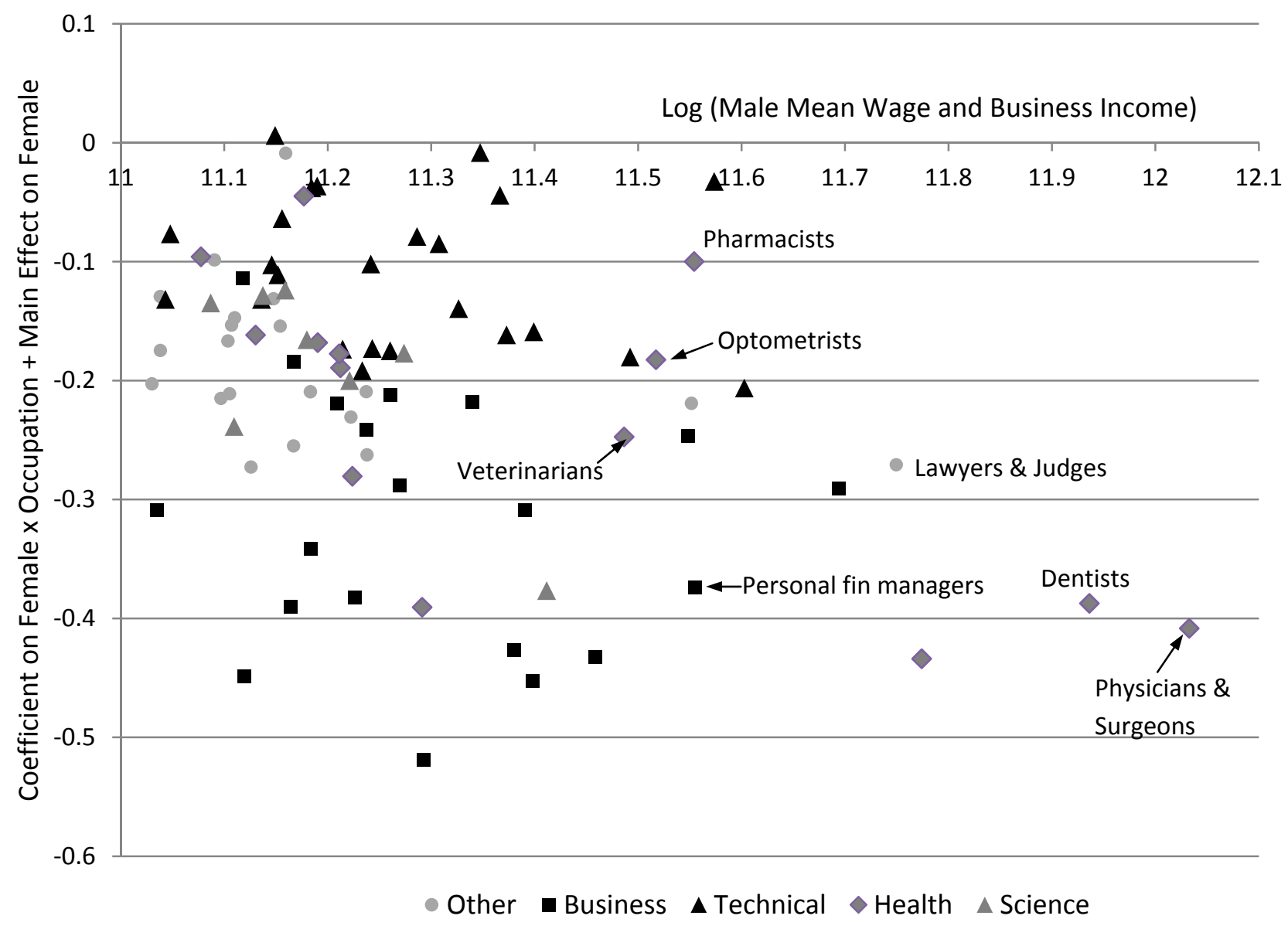

Source: American Community Survey $(2006,2007,2008)$

Notes: The vertical axis is the coefficient on female $\times$ occupation plus the main coefficient from a (log) annual earnings (wage plus business and farm income) estimation on female full-time (> 35 hours), full-year (> 40 weeks) workers. The covariates included are age, age squared, and race. The regressions were run over 3,176,730 individual observations including all occupations. The occupations in this figure account for about 800,000 of the total group. The main effect on the female dummy variable is -0.2026 . The entire sample contains 465 census occupations. The group shown in the figure consists of only the top 87 occupations ranked by male wage and business income. 


\section{References}

American Medical Association. Various years. Physician characteristics and distribution in the US. (Year) edition. AMA Press.

American Veterinary Medical Association. 2007. AVMA report on veterinary compensation. American Veterinary Medical Association.

Bertrand, Marianne, Claudia Goldin, and Lawrence F. Katz. 2010. "Dynamics of the gender gap among young professionals in the corporate and financial sectors," American Economic Journal 2 (July): 228-55.

Bottero, Wendy. 1992. "The changing face of the professions? Gender and explanations of women’s entry to pharmacy,” Work, Employment, and Society 6 (September): 329-46.

Cull, William L., Karen G. O’Connor, and Lynn M. Olson. 2010. “Part-time work among pediatricians expands,” Pediatrics 125 (January): 152-57. Published online Dec. 14, 2009; DOI: 10.1542/peds.2009-0767.

Freeman, Brian. 2007. The ultimate guide to choosing a medical specialty. $2^{\text {nd }}$ edition. NY: McGraw Hill Medical.

Fulda, Thomas (1974). “Prescription drug data summary, 1974.” U.S.: G.P.O.

Goldin, Claudia, and Lawrence F. Katz. 2011. “The career cost of family.” NBER Working Paper, forthcoming.

Goldin, Claudia, and Lawrence F. Katz. 2008. “Transitions: Career and family life cycles of the educational elite,” American Economic Review Papers \& Proceedings 98 (May): 363-69.

Iserson, Kenneth V. 2006. Iserson's getting into a residency: A guide for medical students, $7^{\text {th }}$ Edition. Tucson, AZ: Galen Press.

Kapantais, Gloria. 1982. "Summary data from the national inventory of pharmacists: United States, 1978-79." Vital and Health Statistics of the National Center for Health Statistics. Number 85 (October 8).

Midwest Pharmacy Workforce Research Consortium. 2000. National pharmacists workforce survey, 2000: Final report. Pharmacy Manpower Project, Inc. (August). 
Mincer, Jacob, and Solomon Polachek. 1974. “Family investments in human capital,” Journal of Political Economy 82 (March-April): S76-S108.

Mott, David A., William R. Doucette, Caroline A. Gaither, Craig A. Pedersen, and Jon C. Schommer. 2002. "A ten-year analysis of pharmacist participation in the workforce." American Journal of Pharmaceutical Education 66 (Fall): 223-33.

Northrup, Herbert R., Douglas F. Garrison, and Karen M. Rose. 1979. Manpower in the retail pharmacy industry. Philadelphia PA: University of Pennsylvania, Wharton School Industrial Research Unit.

Rosen, Sherwin. 1986. “The theory of equalizing differences.” In O. Ashenfelter and D. Card, eds., The handbook of labor economics, vol. 1, chap. 12. Amsterdam: Elsevier Publishers: 641-92.

Smith, Michael Ira, Albert I. Wertheimer, and Jack E. Fincham,, eds. 2005. Pharmacy and the U.S. health care system. $3^{\text {rd }}$ edition. New York: Pharmaceutical Products Press.

U.S. Department of Health, Education and Welfare, Public Health Service, Health Services and Mental Health Administration. 1969. Pharmacy manpower, United States 1966. U.S.: G.P.O.

U.S. Department of Health, Education and Welfare, Public Health Service, Health Resources Administration. 1978. Pharmacy manpower resources. U.S.: G.P.O.

U.S. Department of Health and Human Services. 2000. Report to Congress: The pharmacist workforce: A study of the supply and demand for pharmacists. (December) U.S.: G.P.O. 